Portland State University

PDXScholar

5-19-1975

\title{
The Development of an Evaluational Process for the Group Home Project of the Northeast Multnomah District of Childrens' Service Division
}

\author{
Lucinda E. McKitrick \\ Portland State University \\ Richard S. Barasch \\ Portland State University \\ Lon J. Lembert \\ Portland State University
}

Follow this and additional works at: https://pdxscholar.library.pdx.edu/open_access_etds

Part of the Social Work Commons

Let us know how access to this document benefits you.

\section{Recommended Citation}

McKitrick, Lucinda E.; Barasch, Richard S.; and Lembert, Lon J., "The Development of an Evaluational Process for the Group Home Project of the Northeast Multnomah District of Childrens' Service Division" (1975). Dissertations and Theses. Paper 1838.

https://doi.org/10.15760/etd.1837

This Thesis is brought to you for free and open access. It has been accepted for inclusion in Dissertations and Theses by an authorized administrator of PDXScholar. Please contact us if we can make this document more accessible: pdxscholar@pdx.edu. 
THE DEVELOPMENT OF AN EVALUATIONAL PROCESS FOR TIL GROUP HOME PROJECT OF TIE NORTHEAST MULTNOMAH DISTRICT OF CHILDRENS' SERVICE DIVISION

\author{
by \\ LUCINDA E. MCKITRICK \\ RICHARD S. BARASCH \\ LON J. LEMBERT
}

\begin{abstract}
A practicum submitted in partial fulfillment of the requirements for the degree of
\end{abstract}

MASTER OF SOCIAL WORK

Portland State University

1975 
TO THE OFFICE OF GRADUATE STUDIES AND RESEARCH:

The members of the Committee approve the practicum of

Lon Lembert, Lucinda McKitrick, and Richard Barasch presented May 19,1975 .

Nancy Kolloff

Jygy And 


\section{ACKNOWLEDGEMENTS}

We wish to thank Judy Anderson, director of the Northeast Multnomah District's Group Home Project. We would also like to thank the project's Social Workers; Al Belais, Carolyn Clark, and Joyce Larson, as well as the Project's Providers and Group Home Members who participated in our study and provided valuable assistance in our endeavors.

We would especially like to thank Nancy Koroloff for her time and understanding in advising us. 
TABLE OF CONTENTS

PAGE

ACKNOWLEDGEMENTS . . . . . . . . . . . . . . . . . . . . iii

LIST OF TABLES . . . . . . . . . . . . . . . . . . . . . . . . . $v$

CHAPTER

I INTRODUCTION

II PROCEDURES . . . . . . . . . . . . . . . . . . . . . . 5

III DATA ANALYSIS . . . . . . . . . . . . . . . 10

IV DISCUSSION OF PROCEDURES . . . . . . . . . . . . 28

V CONCLUSIONS . . . . . . . . . . . . . . . . . . . . 32

VI APPENDIX A - PRE-TEST INSTRUMENTS

AND STATISTICAL DATA . . . . . . . 35

Vit APPEndix B - REVISEd InStRUMENTS . . . . . . . . . . 53 


\section{LIST OF TABLES}

TABLE

PAGE

I Presenting Problems of Group Home Members to

Program Entry . . . . . . . . . . . . . . . . .

II Group Home Member Daily Schoo1 Attendance - Group

Home Member Viewpoint . . . . . . . . . . . . 14

II Group Home Member Daily Schoo1 Attendance - Provider Viewpoint . . . . . . . . . . . . . . . 15

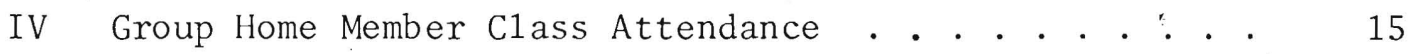

V Group Home Member Class Attendance - Teacher Viewpoint . . . . . . . . . . . . . . . . . . 16

VI Group Home Member Attitude Toward Schoo1 - Group. Home Member Viewpoint... . . . . . . . . . 17

VII Group Home Member Attitude Toward Schoo1 - Provider Viewpoint . . . . . . . . . . . . . . . . . .

VIII Group Home Member Attitude Toward School - Teacher Viewpoint . . . . . . . . . . . . . . . . . .

IX Teacher Rating of Group Home Member C1assroom Behavior . . . . . . . . . . . . . . . . . .

$\mathrm{X}$ Teacher Rating of Group Home Member Interest in School. . . . . . . . . . . . . . . . . . . . .

XI Teacher Rating of Group Home Member Academic Progress . . . . . . . . . . . . . . . . .

XII Teacher Response to General Classroom Behavior of Student . . . . . . . . . . . . . . . . .

XIII Provider Response to the Nature of Group Home Members' Peer Relationships . . . . . . . . . . 21

XIV Group Home Members' Identification of Friends . . . . . 22

XV Group Home Members' Perception of Provider's Motivation for becoming Provider . . . . . . . . . . 


\section{LIST OF TABLES (Continued)}

TABLE

PAGE

XVI Response to how Group Home Members follow Suggestions and Ideas of Providers as seen

by both Group Home Members and Providers . . . . . . 24

XVII Topics Discussed in Group Home . . . . . . . . . . . . 25

XVIII Group Home Members' Perception of Social Worker . . . . 26 


\section{CHAPTER I}

\section{INT RODUCT ION}

Social service agencies have long recognized the need for services to the adolescent. Growing public concern over juvenile delinquency, teen-age drug abuse and the increasing acknowledgement of a teen-age subculture makes this a challenging area for social service workers. Acting-out adolescents pose particularly difficult casework problems because of their general unwillingness to seek help of their own volition. There are limited resources for these clients and successful treatment is often seen as extremely difficult because their particular set of problems are interpreted as the result, of parent failure.

The establishment of a relationship with a caring adult may be difficult for an adolescent to achieve. Professionals involved in adolescent treatment may find themselves working very hard to develop the level of trust that is so vitally needed by this special population. Developmentally, some adolescents are going through a period during which they rebel against parental authority figures and respond more strongly to peer group pressure. Effective treatment of the adolescent must take these factors into account.

Traditional methods of intervention with acting-out adolescents who are unable to maintain themselves in their own environment are residential treatment and foster care. 
Foster care enables an adolescent client to remain in a family system within the regular community. Good foster parents for adolescents are difficult to find, particularly those willing to deal with acting-out behavior. In addition, social worker caseloads for these clients are usually quite large, making treatment efforts more sporadic.

Residential treatment, the other alternative care approach for adolescents, provides a highly structured and planned treatment environment with the presence of a peer group for learning other modes of behavior. Residential treatment centers are usually removed from the center of the community and are the most expensive mode of treatment.

A relatively new alternative approach for teenagers is group home care. Such programs attempt to combine the best aspects of foster care and residential treatment. The troubled adolescent is placed in another family system with other clients and remains within the community. This affords him or her the opportunity to learn new appropriate behavior within a more normal living environment. The peer group in each home can be utilized for learning new ways of dealing with problems with casework services as an aid to this end. Group home care is less expensive than residential treatment but still provides small caseloads for social workers, thus allowing more planned, systematic and effective services.

Childrens' Services Division of the State of Oregon is involved in a group home project. They have to date nine group homes in operation within Multnomah County. Their staff consists of a director, three social workers and the group home provider staff. The project is relatively new, set up in January of 1974. Since the project would be evaluated for refunding by the State Legislature in the spring of 
1975, they needed research and evaluation of their program to present to the Legislature. As of summer 1974, there were no demographic descriptions of their client population or evaluative data on the relative success of their program. Evaluative research is valuable for various reasons and is built into the Group Home Project requirements. Evaluation enables all involved to look at what the program does well and where changes might be necessary. It also necessitates careful record keeping, thereby permitting a more accurate assessment of the changes in the clients served. Internal evaluation provides consistent and objective feedback on the effectiveness of client services.

An accurate evaluative study of the changes in these clients before and after entering the Group Home Project was not feasible because the pre-existing data was not available. There was also the problem of measuring success. What are the standards of success for an individual client and what are they for the total program? Could success be accurately measured in such a small population? The primary goal for this practicum was the development of an evaluative system that would establish descriptions of the type of client who entered the Group Home Program and some criteria for success in that program. In developing this system, it was necessary to design instruments to measure behavioral changes and attitudes and also to collect descriptive data. Such a system should be as comprehensive as possible while remaining fairly simple and easy to implement.

A secondary goal was to pre-test the evaluative system and gather data for the use of the Group Home Project. The instruments could be used continuously in an on-going evaluative process with pre-test data 
as a standard by which to set more definite objectives and evaluation of the program. Finally the information gathered could be valuable for the 1975 Legislative review. 
CHAPTER II

PROCEDURES

The first step in developing an evaluation process was to decide what to look for in terms of outcomes. The adolescent population involved in the program is small and did not lend itself to a precise study of behavioral and attitude changes before and after entering the program. It was necessary to provide a process for establishing criteria for success, and assessing change, as well as gathering consistent descriptive data about the client population. Instruments were designed with this end in mind.

If an accurate before and after study of the Group Home Project is practically and statistically not feasible, how is it possible to define and measure the success of the program? Program evaluation systems essentially exist to provide data that indicates how closely the outcomes of a project match the stated objectives. Therefore it became necessary to decide upon specific areas in which to establish more clear-cut objectives. The first step in this process was to single out broad areas of concern agreed upon as important for maturing young adults. After talking to the Social Workers, Providers and Group Home Members, and the program Administrator to get input on these factors, it was decided to concentrate on three significant areas in which attitudes and behavior could be measured: the school, the community and the Group Home itself. 
This feedback was valuable in developing the questionnaires for additional reasons. The focus of the study would be more accurate, and the Group Home Members would have a clearer understanding of the study. All people involved were cooperative. It was especially important that the Group Home Members' opinions be sought since it hopefully gave them a feeling of being part of a project and not merely the object of "nosy". scrutiny.

Education is an important factor in an adolescent's world. He or she spends most of the day in school, meets friends and forms peer relationships. How a Group Home Member functions at school is important to his or her development as a member of society. This did not mean that Group Home Members should have college level career goals or honor list grade averages. Instead it was decided that the evaluation should look at measurable behaviors in the school atmosphere. This could'include attendance records, grade averages, involvement in school activities and attitudes toward school staff, fellow students and subject matter.

Community involvement was also an area chosen to be evaluated. The negative aspects of community contact such as various types of involvement with law enforcement agencies as well as positive involvement with the community such as participation in NYC, or volunteer community service were measured.

Success within the home itself is more difficult to measure since such things as self-concept and the nature of personal relationships are rather intangible and hard to evaluate. Stability in the home was an important factor to consider. Also important was how he or she handled group and Provider decisions and individual responsibilities. 
Some material was included to get at the nature of the Group Home Member's relationships with others in his immediate environment, friends from within and without the home, Providers, teachers and Social Workers.

The main purpose in singling out these areas was to collect primarily descriptive data, so that standards could be set for future evaluative efforts. However, without set standardized objectives or accurate data on the Group Home Members before entering the program, the attempt was made to assess some change. This was done in three ways. A face sheet was developed to obtain data on each new in-coming participant. The instruments would contain questions of a comparative nature. The instruments if used again during established time intervals would provide for comparative data.

It has already been established that the focus of the evaluative process is on the Group Home Member. An important point to consider is that although the instruments seem at times to be focused on individual behavior and attitudes, the main interest was in establishing a group level of success. Important individuals in the Group Home Members' collective environment are Providers, teachers and Social Worker. Instruments were developed for the teachers and Providers as a perceptional check for the Group Home Members' own report. An instrument for the Social Workers was not developed because of the amount of time involved in their responding to each client and because they would most probably be the ones administering the questionnaires in the future. Therefore the focus of all instruments would be on the Group Home Member, but respondents would include Providers and teachers . 
The final plan included four instruments administered to three different sub-populations, teachers, Providers and Group Home Members. The face sheet information was compiled from case records. The teacher quesionnaire focused on school related issues. The Provider and Group Home Member questionnaire focused on all three areas previously mentioned, that is school, home and community. Providers would be responsible for filling out one questionnaire for each member of their home. It was decided that there would be questionnaires for two teachers per Group Home Member. Because of the difficulties in getting the school administration's permission to talk to teachers, the houseparents took responsibility for administering teacher questionnaires to first and last period class teachers so as to make the results as random as possible.

Confidentiality became an issue because without such assurances it would be difficult to receive open and honest responses to the questions. The teacher questionnaires could not be confidential which posed problems which will be discussed later.

Various types of questions were utilized in the instruments, Likert scale, checklists, noted frequencies and some short answer. On the Group Home Members' instrument the language was made relatively simple so that most adolescents would understand the questions. For instance "friends" or "kids your own age" was used rather than the word "peer".

The pre-test population consisted of 15 of the Group Hóme Members, those who had been residents since January 1, 1975. The data gathering was conducted in late February so that all had been in the home at least six or seven weeks. The interviewer went to four group 
homes and administered the questionnaires. Confidentiality was stressed as well as the fact that the program was being evaluated and not the individual progress of each Group Home Member or the competence of the Providers. Generally, all were very cooperative during testing, which took about 35 minutes.

After conducting the pre-test, the data was analyzed primarily in terms of frequencies and percentages. Some attention was paid to comparing perceptions of the Providers, teachers and Group,Home Members in terms of credibility. This data would then be available for descriptions of the present population and for future evaluative studies . 
CHAPTER III

DATA ANALYSIS

A decision was made to analyze the data according to the three areas of concern, school, home and community. A special section will also be devoted to the face sheet. Some of the data will be presented in tables within this chapter. All of the data appears in the Appendices. Please consult Appendix A for original testing instruments and a complete listing of data obtained from the teacher, Group Home Member and Provider questionnaires as well as the face sheet. Appendix B contains copies of the revised instruments.

\section{FACE SHEET ANALYSIS}

The idea for developing a face sheet was to provide a factual view of what the Group Home Member was like before entering the group home. The face sheet data was gathered primarily from the Childrens Services Division case records. On many occasions the records lacked specific information concerning the interest areas. The social workers became a secondary data source and were able to provide most of the data that was lacking. The information that was collected through this means has some important drawbacks. Case records are subject to numerous interpretations and methods of recording. The data, therefore, tends to be subjective and non-specific. As the face sheet data was collected, it became necessary to make numerous arbitrary judgements and interpretations concerning the information obtained. The areas dealing 
with school, peer relationships and presenting problems could ordinarily be correlated with the data collected in the questionnaires. The arbitrary nature of the face sheet information greatly reduces the validity of such a correlation.

Our sample population of fifteen Group Home Members consisted of ten girls and five boys. All members of the sample were from a white racial background. The average age of this group was 15.5 years. The youngest Group Home Member at the time of testing was thirteen years old and the oldest was eighteen. Information was gathered on the current status of the family. It was discovered that eleven of the Group Home Member's parents were divorced, two were separated, one couple was together and nothing was available on one set of parents. Information was available on none of the families concerning other siblings. There was an average of 2.7 siblings per family ranging from one other sibling in the family to five other siblings.

An attempt was made to gather information concerning the Group Home Member's previous school experience. At the time of placement in the group homes there was one eighth grader, two freshmen, six sophomores, three juniors, one senior, and two on whom no data could be obtained. An arbitrary means of classification and judging was attempted in order to place the Group Home Members in the education categories of good, average and poor. There were no grades listed in the case record and little reference made to the quality of work that the members of the sample were doing. It was unfair and impossible to attempt to classify these people according to school achievement.

The next area considered was a brief history of the Group Home Members with agencies. In an attempt to note the reasons for referral 
to Children's Services Division, the following information was gathered. Five children were referred because of parental abuse. Three children were self referrals either directly to CSD or through a youth center. Two referrals came from the Juvenile Court system and three referrals were due to parental physical or mental illness.

Most of the Group Home Members experienced other alternatives in living and care situations. Only two adolescents came directly from the family situation to the group homes. Seven members out of fifteen had lived in an extended family structure. Three had received some form of therapy or counseling while still living in the home. Eleven had lived in one or more foster home settings. Three had spent periods of time in residential treatment centers and one girl was raised by a woman who took children on a private basis.

A list of problem categories was made to make note of presenting problems the Group Home Members had experienced prior to placement in their respective homes. The multiple responses were listed in the following categories.

\section{TABLE I}

Presenting Problems of Group House Members Prior to Program Entry

\begin{tabular}{lllr}
\hline Response & N* & Response & N \\
\hline School Discipline & & Prental Neglect & 11 \\
Problems & 4 & Parent Abuse & 2 \\
Low School Achievement & 5 & Inadequate Social Skills & 3 \\
School Truancy & 5 & Poor Peer Associations & 5 \\
Runaway & 9 & Difficulty with Authority & \\
Drugs & 2 & Figures & 3 \\
Beyond parental Control & 5 & Manipulative Behavior & 3 \\
Sexual Acting Out & 1 & Other & 1 \\
\hline
\end{tabular}

* The letter $\mathrm{N}$ will be used throughout to mean number of responses. 
An attempt was made to ascertain the level of parental involvement in the treatment program and it was found that seven of the fifteen parent sets were not involved in any way with the Group Home Provider or the child. Six parents maintained varying degrees of contact with the child, no family unit was involved in family therapy and only two single parents were involved in individual counseling.

Corresponding to this information was a section which specified the goals for care after leaving the group home. Expectations were held for only two Group Home Members to return to their original families. There were plans for one child to return to foster care and seven were expected to reach self-sufficiency. Plans were unspecified for five of the Group Home Members.

Peer group associations were also recorded in the categories of good, average and poor. Categorizing was somewhat arbitrary but in most instances specific reference was given in the case records. There were two, however, that neither Social Workers nor case records could give information on. Five of the fifteen Group Home Members had good peer associations, three had average associations and five had poor peer associations.

Finally, the children were listed according to the number of months they had lived in the group home setting. The fifteen averaged 5.5 months of residence with three months being the shortest time in attendance and twelve months the longest.

\section{QUESTIONNAIRE DATA}

The total size of the sample was fifteen Group Home Members. Accompanying their questionnaires were a similar number of questionnaires 
from the Group Home Providers. Completed questionnaires were received from twenty-five of the Group Home Members' teachers. For varying reasons, five teachers did not respond to the questionnaire. This affected to some extent the validity of the data and will be discussed later with the teacher questionnaire. The sample population of Group Home Members attended school in a variety of settings. Eleven Group Home Members were attending school in traditional settings, three attended alternative schools and one attended grade school. The resulting, variations of curriculum and grading practices prevented standardization of data and made measurement somewhat arbitrary.

\section{A. School Data}

\section{School Attendance}

School attendance was measured on al1 three of the questionnaires. Attendance was divided into two areas. The first area was daily attendance at school or the number of times the student did not appear at school. The other category dealt with class attendance which asked the number of classes missed. This recognizes the fact that attending school does not guarantee that all classes were attended. The first category of daily attendance was measured on the Provider and Group Home Member questionnaire.

TABLE II

Group Home Member Daily School Attendance Group Home Member Viewpoint

\begin{tabular}{lrr}
\hline Response & N & $\%$ \\
\hline Missed 0 Days & 3 & 20 \\
Missed 1-10 Days & 9 & 60 \\
Missed $10-20$ Days & 2 & 13 \\
Missed 20 or More Days & 1 & 7 \\
\hline
\end{tabular}


TABLE III

Group Home Member Daily Schoo1 Attendance Provider Viewpoint

\begin{tabular}{lrr}
\hline Response & $\mathrm{N}$ & $\%$ \\
\hline & & \\
Missed 0 Days & 3 & 20 \\
Missed $1-10$ Days & 11 & 73 \\
Missed $10-20$ Days & 0 & 0 \\
Missed 20 or More Days & 1 & 7 \\
\hline
\end{tabular}

Both the Providers and Group Home Members are in agreement on daily school attendance with both responding that the number of days missed fa11s within the categories of 10 days or less. This may indicate a positive level of awareness and communication between Provider and House Members concerning school activities.

\section{C1ass Attendance}

Class attendance was measured on the Group Home Member and Teacher questionnaires. When asked about class attendance, students and teachers replied in the following way.

TABLE IV

Group Home Member C1ass Attendance -

Group Home Member Viewpoint

\begin{tabular}{lrr}
\hline Response & N & $\%$ \\
\hline Miss 0 Classes & 8 & 61 \\
Miss 1 Per Week & 3 & 23 \\
Miss 2-5 Per Week & 0 & 0 \\
Miss 1 Per Day & 1 & 8 \\
Miss 2 Per Day & 0 & 0 \\
Miss 3 or More Per Day & 1 & 8 \\
\hline
\end{tabular}


TABLE $V$

Group Home Member Class Attendance Teacher Viewpoint

\begin{tabular}{lrr}
\hline Response & N & $\%$ \\
\hline Miss 0 Classes & 12 & 48 \\
Miss 1-3 Classes & 5 & 20 \\
Miss 4-6 Classes & 3 & 12 \\
Miss 7-10 Classes & 3 & 12 \\
Miss 11-20 Classes & 1 & 4 \\
Miss More Than 21 Classes & 1 & 4 \\
\hline
\end{tabular}

Group Home Providers reported that $61 \%$ attended all of their classes when they went to school. $84 \%$ reported that they missed one class or less per week. The sampling of teachers indicated that $48 \%$ of the sample attended all their classes when at school. $20 \%$ missed only 1-3 classes all quarter. Any correlation between Group Home Members and Teachers is impossible due to an absence of five Teacher questionnaires. Two teachers were to have filled out questionnaires for each student. Percentages of the teacher data is therefore based on a theoretical sample of $12-1 / 2$ students.

In general, $66 \%(10)$ of the students felt that their class attendance had been the same this quarter as last quarter. $27 \%$ or 4 students felt their attendance had improved. (Please see Appendix A Group House Member Questionnaire). Of the seven who commented on their reason for attendance, four (4) listed the influence of the Providers as the reason. In general this indicates that Group Home Members perceived themselves to be doing better on school attendance now, compared to before the program. The students attitude toward school was solicited on all three of the questionnaires with the following results. When asked how they liked school compared to last quarter, Group Home Members answered: 
3. School Attitude

TABLE VI

Group Home Member Attitude Toward School -

Group Home Member Viewpoint

\begin{tabular}{lcc}
\hline Response & $\mathrm{N}$ & $\frac{\%}{\%}$ \\
\hline Much Better & 3 & 20 \\
Better & 5 & 33 \\
About The Same & 3 & 14 \\
Not Like It Was & 5 & 33 \\
A Lot Worse & 0 & 0 \\
\hline
\end{tabular}

The Providers were asked to rate their impression of the Group Home Members school attitude and they responded this way:

TABLE VII

*Group Home Member Attitude Toward School Provider Viewpoint

\begin{tabular}{lrc}
\hline Response & $\mathrm{N}$ & $\%$ \\
\hline A Good Deal More Interested & 5 & 36 \\
Somewhat More Interested & 5 & 36 \\
About the Same & 2 & 14 \\
Less Interested & 2 & 14 \\
\hline
\end{tabular}

* Due to one "no response" the percentages are based on a sample of fourteen.

Teachers were a1so asked to rate the Group Home Members' school attitude using attention and input as the measurement. They responded in the following way:

TABLE VIII

Group Home Member Attitude Toward School Teacher Viewpoint

\begin{tabular}{lrc}
\hline Response & N & $\%$ \\
\hline Active and Attentive & 9 & 37 \\
No Input, but Attentive & 12 & 50 \\
No Input, Inattentive & 3 & 13 \\
\hline
\end{tabular}


$53 \%(8)$ of the Group Home Members described school as better than last quarter. In conjunction with the student attitude question, Group Home Members were asked to comment on their teachers, hoping to ascertain the teachers influence on attitude. $40 \%(6)$ felt better about their teachers. When asked about activities outside of class but generated by school, eight said they had done outside reading, six mentioned they watched a television show suggested by their teachers. The Providers felt that $72 \%(10)$ had a more positive attitude toward school this quarter. $37 \%$ of the teachers perceived the Group Home Members attitudes as being neutral to positive in terms of attention and input.

In a question concerning classroom behavior, $45 \%$ of the teachers saw their student's classroom behavior as improved. $45 \%$ saw their behavior as the same.

TABLE IX

Teacher Rating of Group Home Member Classroom Behavior

\begin{tabular}{lrr}
\hline Response & $\mathrm{N}$ & $\%$ \\
\hline & & \\
Improved Greatly & 4 & 18 \\
Improved Somewhat & 6 & 27 \\
Remained The Same & 10 & 45 \\
Regressed Somewhat & 2 & 10 \\
Regressed A Great Deal & 0 & 0 \\
\hline
\end{tabular}

Another question asking the teachers impression of the students interest in class compared to last quarter got the following response:

TABLE X Teacher Rating of Group Home Member Interest in School

\begin{tabular}{lrr}
\hline Response & $\mathrm{N}$ & $\frac{\%}{\%}$ \\
\hline Improved A Great Deal & 4 & 19 \\
Improved Somewhat & 5 & 24 \\
Remained The Same & 9 & 43 \\
Regressed Somewhat & 4 & 14 \\
Regressed A Great Deal & 0 & 0 \\
\hline
\end{tabular}


$42 \%$ felt the Group Home Members interest in school had improved. $14 \%$ felt they had seen some regression in school interest. The attitude of the Group Home Member toward school appears in general to have improved in comparison to their school experiences last quarter. Group Home Members, Teachers and Providers are consistent in their agreement that the majority of the Group Home Members are experiencing a more positive attitude toward their school programs. Two factors that were noted as influences on Group Home Member attitudes were their Teachers and the Providers.

\section{School Achievement}

This portion of the study ran into enough problems that data became insignificant. Only five members of the sample were able to furnish actual grades from last quarter. The five were from a traditional high school and a cumulative point index of 1.96 was achieved. Twelve of the twenty-five teachers listed grades for their students which resulted in a cumulative point index of 1.83. Other responses were as follows: 1) Straight B's, 2) B's and C's, 3) Doing well, (4) Mediocre.

The teachers were asked to describe the general academic progress of the students with the following results:

TABLE XI

Teacher Rating of Group Home Member Academic Progress

\begin{tabular}{lcc}
\hline Response & N & $\%$ \\
\hline Excellent Progress & 2 & 10 \\
More Than Satisfactory & 2 & 10 \\
Satisfactory Progress & 7 & 33 \\
Some Academic Progress & 8 & 37 \\
No Academic Progress & 2 & 10 \\
\hline
\end{tabular}


$53 \%$ of the Teachers felt that the students were making at least satisfactory progress. $20 \%$ of the teachers felt that the students were making more than satisfactory progress.

School achievement remains a very arbitrary variable due to lack of achievement data. Available data indicates that the Group Home Members' academic success is very average based on the traditional four point system. Without previous data however, it is impossible to judge whether mixed academic success is an improvement or deterióration from previous school quarters.

\section{B. Group Home Life}

The second consideration in the evaluation of the group home project was to determine the Group Home Members' adaptation to living in the group home. Attempts were made to determine the quality of a variety of factors affecting the Group. Home Members' living situation in the group home.

\section{Peer Relations}

A primary factor in the adaptation to group home life was the relationship of the Group Home Member's relationship with his/her peers. In order to measure this factor the questionnaires were utilized.

One aspect of peer relationships was the leadership qualities of the Group House Members. It was interesting to compare the teacher's questionnaire concerning the Group House Member's classroom behavior, which measured an aspect of the Group House Member's leadership qualities with the provider's response to the general question conceming the Group House Member's peer relationships. The teachers felt that $25 \%$ of 
their students, "provided positive leadership", while the providers felt that $25 \%$ of the Group House Members were regarded by their peers as leaders.

TABLE XII

Teacher Response to General Classroom Behavior of Student

\begin{tabular}{lcc}
\hline Response & $\mathrm{N}$ & $\%$ \\
\hline $\begin{array}{l}\text { One of positive leadership, directing the class } \\
\text { towards positive behavior. }\end{array}$ & 6 & 25 \\
$\begin{array}{l}\text { One of negative leadership, directing the class } \\
\text { towards negative behavior. }\end{array}$ & 2 & 8 \\
$\begin{array}{l}\text { One of negative and positive leadership, direct- } \\
\text { ing the class towards negative and positive }\end{array}$ & 3 & 13 \\
$\begin{array}{l}\text { behavior. } \\
\text { Neither positive nor negative leadership, but can } \\
\text { be influenced by negative leadership. }\end{array}$ & 10 & 42 \\
\begin{tabular}{l} 
Other \\
\hline
\end{tabular} & 3 & 13 \\
\hline
\end{tabular}

TABLE XIII

Provider Response to the Nature of Group Home Member's Peer Relationships

\begin{tabular}{lcc}
\hline Response & N & $\%$ \\
\hline Regard him or her as a leader & 5 & 25 \\
$\begin{array}{l}\text { Generally like him or her, accept him or her } \\
\quad \text { as part of the group }\end{array}$ & 9 & 45 \\
He or she has few friends & 5 & 25 \\
Peers generally dislike him or her. & 1 & 5 \\
\hline
\end{tabular}

The most significant statistic in Table 8 is the fact that $42 \%$ of the sample have, "neither positive nor negative leadership, but can be influenced by negative leadership." This might indicate that a sizeable portion of the sample are not leaders, and tend to follow other's behavior, frequently (as interpreted by the teachers) in a "negative" fashion . 
An important point was the Group Home Member's response as to how they felt they were accepted by their peers as well as to how they themselves accepted their peers. Thierteen of the sample of fifteen Group Home Members responded within the range of, "I respect some of my peers," through "I respect all of my peers." This high agreement signifies a rather high reciprocal relationship of the Group House Member's perception of their acceptance by their peers with their acceptance of their peers.

Related to this question of peer group acceptance was the Provider's response that thirteen out of fifteen Group House Members had made "Some or much improvement" in their peer group relations since they had been living in the group home.

It was interesting to note whom the Group Home Members felt their best friends were. (They could check as many categories as they liked).

TABLE XIV

Group Home Member's Identification of Best Friends

\begin{tabular}{lrr}
\hline Response & N & $\%$ \\
\hline Schoolmates of mine & 13 & 37 \\
Live in my neighborhood & 7 & 20 \\
Belong to Organizations I belong to & 0 & 0 \\
Live in the Group Home & 7 & 20 \\
Live in the neighborhood I used to live in & 6 & 17 \\
Other & 2 & 6 \\
\hline
\end{tabular}

Most of the factors indicate the conclusion that the group home living experience has generally led to an improvement in the Group Home Member's peer relationships. Although it has been determined that many of the Group Home Members are susceptible to negative leadership, other factors leave the impression the peer relationships are generally improving. Certainly this is an extremely important goal of any treatment program . 


\section{Provider Relationships}

Another factor related to the Group Home Member's adjustment to the group home was their relationship to the Providers. A question was asked conceming how the Group Home Members perceived the Providers. The two most popular responses elicited from the Group Home Members were that they saw the Providers as an, "Adult friend," and as a "Parent figure." When the providers were asked how they thought the Group Home Members perceived them, once again the two most responded to answers were, as an "adult friend", and as a "parent figure".

Another point of interest was simply how the Group Home Members described their relationship with their providers. Of course the perception of this relationship can be quite subjective, depending upon the particular events occurring at the time between the Provider and the Group Home Member. However, it appears that the Group Home Members generally see the Providers in a positive manner. Eleven of the fifteen (73\%) liked them both, three were ambivalent or negative about one of the two providers, and one Group Home Member responded that she/he disliked them both.

Related to the above question is that generally the Group Home Members perceived the Providers as choosing their type of work for positive, altruistic reasons.

TABLE XV

Group Home Member's Perception of

Provider's Motivation for Becoming Providers

\begin{tabular}{lrc}
\hline Response & $\mathrm{N}$ & $\%$ \\
\hline They like teenagers & 9 & 24 \\
They get money for it & 5 & 13 \\
They are concerned about me & 8 & 21 \\
They feel they are helping people & 12 & 32 \\
They like being parents & 4 & 10 \\
\hline * Group Home Members could respond to as many categories as \\
they felt appropriate.
\end{tabular}


A factor that indirectly has previously been tested was the level of trust between the Group Home Member and Provider. This has been seen through the similarity in perceiving various aspects of Group Home life by the Providers and Group Home Members. Ten (66\%) of the Group Home Members felt as though they could talk over some, if not all, of their feelings and problems with their Providers. The Providers, however did not see themselves as trustworthy in the eyes of the Group Home Members. Only $46 \%$ of the Providers responded "yes" to the question as to whether they felt the Group Home Members trusted them with personal information. However, another 33\% did respond, "occasionally" to the same question concerning whether the Group Home Member trusted them with personal information.

The level of influence of the Provider with the Group Home Member was questioned in the instruments. Apparently there is a rather similar perception as to how the Group Home Member follows the Provider's ideas and suggestions.

TABLE XVI

Responses as to How Group Home Member Follows Suggestions and Ideas of Providers as Seen by Both Group Home Member and Provider

\begin{tabular}{lccccc} 
Person & & \multicolumn{4}{c}{ Response } \\
\cline { 3 - 5 } & never & seldom & sometimes & often & always \\
$\begin{array}{l}\text { Group Home } \\
\text { Member }\end{array}$ & 0 & 1 & 3 & 11 & 0 \\
Provider & 0 & 0 & 5 & 8 & 2
\end{tabular}

The topics of discussion in the group home gives the impression that the Group Home members were subject to a great range of contemporary topics while living in the group home. However, it appears that the Providers feel they were discussing these subjects somewhat more 
often than the Group Home Members perceived it. The providers felt that every one of the topics were covered, with the exception of one, more often than did the Group Home Members.

TABLE XVII

Topics Discussed in Group Home

$\underline{\text { Response }}$

$\frac{\text { Person }}{\text { Group Home }} \frac{}{\text { Member(N) Provider }(\mathrm{N})}$

Sex Education and Information

$\begin{array}{rr}7 & 13 \\ 9 & 10 \\ 9 & 13 \\ 8 & 14 \\ 10 & 12 \\ 13 & 15 \\ 14 & 15 \\ 13 & 15\end{array}$

The pretest has shown a generally caring, trusting, and stimulating relationship between the Provider and Group Home Members. Certainly the relationship between the Provider and Group Home Mèmber is of paramount importance to the Group Home Project. This is an extremely important factor due to the great many of neglectful and mistrusting relationships these adolescents have had with adult figures in the past.

\section{Group Home Member-Social Worker Relationships}

The next topic of interest was the Group Home Member's relationship to their social worker. The Providers, supposedly an objective and neutral indicator, saw no Group Home Member-Social Worker relationship deteriorating since the Group Home Member had become a part of the Group Home. The Providers saw $27 \%$ of the Group Home Member-Social Worker relationships not changing while being in the group home, while the rest of the relationships were perceived as having some or much improvement. 
TABLE XVIII

Group Home Member's Perception of Social Worker

\begin{tabular}{lrr}
\hline Response & N & $\%$ \\
\hline Someone with power over me & 4 & 27 \\
Someone you respect because the person is & 1 & 7 \\
$\quad$ an expert & 10 & 67 \\
A Friend & 0 & 0 \\
The Enemy & 0 & 0 \\
A Parent & 0 & 0
\end{tabular}

The Group Home Members generally perceived the Social Worker in a positive manner and appeared to trust them. However, it was interesting to note that the most popular responses of the Group Home Member towards the Social Worker fell into two polarities. Most of the Group Home Members perceived their Social Worker as a "friend", yet the second highest category was "someone with power over me".

Other responses by the Group Home Members concerning their Social Worker were, "someone with good intentions, but not to depend on totally", "can trust to a degree", "have respect for", and "people like her". Once again it appears as though the Group Home project has had another positive effect. There could be a variety of factors, certainly including the relatively small caseload, but there does appear to be a rather satisfying and growing relationship between the Social Workers and Group Home Members.

\section{Community Life}

Our last category of concern was the Group Home Members' relationship to the community. In a negative sense, $26 \%$ of the Group Home Members had some contact with law enforcement agencies since living in the group home. Of the four Group Home Members who had contact with the 
law it was a result of running away, curfew, assault, and "jaywalking and bomb threat to telephone company".

Positively, the Group Home Member's contact with the community included such activities as regular, steady employment, informal jobs such as babysitting, a member of the school/community council, and informal community contacts. This information was obtained from verbal interview with the Group Home Members after they had completed their questionnaire. 


\section{CHAPTER IV}

\section{DISCUSSION OF PROCESS}

In the process of administering the instruments certain problems became evident both in the content of the questionnaires as well as in their administration. The discussion of this chapter will, deal with these problems and the changes made to facilitate a smoother, more organized process and more accurate data collecting techniques.

After compiling the results of the pre-test and analyzing the information from the face sheets it was necessary to review all four of the instruments. Please consult Appendix B for precise information on these changes. These needed revisions were due to some of the difficulties that the respondents had in answering some of the questions as well as some short-sightedness on the researchers' part. These problems did not become evident until the results of the instruments as a whole were analyzed.

One of the shortcomings of the questionnaires was the failure to standardize the language of the questions within the three instruments. Although it was possible to correlate some of the questions, the vocabulary and categories of the questions in the new instruments are far more similar than those used in the pre-test.

Another difficulty encountered in the pre-test was the redundancy of some of the questions, a few of which were basically attempting to determine the same variable. This problem was quite noticeable in the Provider and Group Home Member instruments. For instance, it was 
discovered that it was possible to combine two questions concerning the Group Home Members' relationship with their Social Worker and still achieve the goal of determing the Group Members' image of their Social Worker.

Related to the above problem was the realization that some of the questions were quite difficult to answer. For instance, in the teacher questionnaire, few were able to answer the question concerning the students' grades, and also few were able to answer this same question in the Provider questionnaires. This was due to the great range of grading systems in contemporary schools. Therefore, the original questions concerning grades were abandoned and more general questions concerned with the students' academic progress were substituted.

One obvious problem in the pre-test was the failure to include a section concerning the positive community experiences of the Group Home Members. Fortunately, it was possible to determine what these experiences were through a verbal discussion between the administrator of the tests and the Group Home Members. The new instruments now include this important variable.

The face sheet was revised after analyzing the descriptive data. The replies to some of the categories established on the original face sheet were found to be similar. For instance, such presenting problems as "beyond parental control" was quite similar to "difficulty with authority figures". A check in one category usually resulted in a check in the closely related category. Therefore, in the interest of streamlining the face sheet wherever possible it was best to eliminate one of the categories.

The face sheet also posed particular difficulties in that it was necessary to glean information from case record material. The 
researchers found themselves rather subjectively selecting out data. Due to the lack of specific recording practices, some information was unobtainable. Also the face sheets were designed with the idea that information would be obtained from case records. If face sheets were automatically filled out with each new placement by the Social Worker, it would be possible to keep more accurate information in a standard format which would then be readily available for future evaluative efforts

In administering the Provider and Group Home Member questionnaires there were other problems involved. It was difficult to arrange times when all members of the Group Home could be there at once. It was possible however, to overcome this by arranging meetings far enough in advance. In the future, Social Workers would be the most appropriate agency personnel to administer the instruments and would be able to pick convenient times such as group meetings for this purpose.

Some Group Home Members ran away from the group home before school questionnaires could be completed. With such mobile and changing population it is difficult to get exact results, especially when several instruments are utilized. Because confidentiality was stressed, it became even more difficult to monitor proper and complete responses. These difficulties will probably continue to be present. However, it is important to remember that a group level of success is being sought and that Social Workers will probably be administering future evaluative procedures. Social Workers are in a good position to monitor as , complete a response as possible and group level evaluation is not as dependent on members staying as individual evaluative efforts. 
The teacher questionnaire was perhaps the most difficult instrument to administer. The Providers were the individuals responsible for contacting the teachers, thus making the procedure more time-consuming and complicated as well as making confidentiality more difficult to maintain. If the Social Worker collected such teacher information, the process would be much smoother and possibly more consistent. Another possibility might be to drop the teacher questionnaire from the total evaluative process if it proves to be unworkable due to unavailable time and manpower. Some information on the teacher questionnaire is redundant and teachers had some difficulties in cooperating with the procedures. Providers generally have good feedback from the schools and their input can be checked against the Group Home Members' perceptions of school related issues. The main value in having the additional teacher input is for a more accurate perceptional check.

These then were the problems and their possible solutions encountered in the process of developing the evaluative system. The final chapter will conclude with an overview of the system and suggestions for its future use. 


\section{CHAPTER V}

\section{CONCLUSIONS}

The final evaluative system contains four revised instruments, one for each Group Home Member and for a Provider in his home, one for two teachers of each Group Home Member and a face sheet. The instruments utilize techniques such as noting frequencies, short answer questions, Likert scale questions and checklists in gathering data. These questions are concerned with establishing information centered around three major areas of functioning, the school, home and community. Some questions are cross-referenced as a perceptional check.

It is recommended that for future use the Social Workers take responsibility for administering the instruments with the option of deleting the teacher questionnaire as mentioned earlier. The face sheet is of particular importance and every effort should be made to collect complete data on each new admission to the program for more consistent and comprehensive information and comparative data purposes. The instruments should be administered in as confidential a manner as possible to insure credibility.

The ideal time to administer the instruments would be at the end of a school term to insure more accurate school related information. This could be done one to three times a year or approximately every three months. The Group Home Members should be residents for this length of time before being evaluated. 
The pre-test was conducted on a testing population consisting of fifteen Group Home Members, twenty-five teachers and four sets of Providers. Only those who had participated in the program since January 1 , 1975 were used in the pre-test sample.

The information obtained gave a descriptive picture of the group homes that was generally positive. Credibility is assumed to be fairly high since Group Home Members', Providers' and teachers' responses matched fairly closely. In the school area, Group Home Members seemed to be maintaining some level of participation. The grade averages are not high and school attendance is sometimes a problem. However, if they go to school they generally attend classes. Generally, the Providers and Group Home Members agree that they view school in a more positive manner than when they entered the program. Providers and teachers had an influence in precipitating this trend. The face sheet, information indicated that Approximately one-third of the Group Home Members had trouble with school related issues, so this data indicates more positive attitudes.

There were some negative aspects of community involvement, particularly in reference to contacts with law enforcement agencies. With two exceptions, however, these contacts were runaway or other minor violations. This information is balanced out by more positive involvement in the community such as jobs and participation in school-related functions .

The information from the home sphere also indicated a positive trend. Generally, a11 populations agreed that there was some improvement in the nature of peer relationships. Group Home Members felt that they were both accepted by and accepting of others. There also seems 
to be a fairly high level of trust between Group Home Members, Providers and Social Workers. This is an especially important piece of information since the face sheets show that many Group Home Members come from broken homes where there is a record of parental neglect. The fact that Group Home Members do have some trust in the adults present in their home environment indicates a positive direction toward more caring and trustful relationships with adults as well as with peers.

The data from the pre-test is largely descriptive in, nature and gives generally positive feedback about the program. Part of the purpose of this study was accomplished by providing this data for the group home project. Hopefully, this information will be valuable for presentation to the Legislature. The other useful aspect of this preliminary study is to suggest more standardized and precise objectives for Group Home care. This sutdy may provide the project with a baseline of information for further evaluations. The second part of the study, that is development of an evaluative process, will hopefully provide the instruments and a procedure for utilization in these later efforts. Group Home care is a rapidly growing altemative care approach directed at meeting the needs of adolescent clients. The preliminary data found in this pre-test suggests that the Group Home Project of Multnomah County Childrens' Services Division is having some positive results. The pre-test also provides some available information for future research efforts and a mechanism for furthering that end. 
APPENDIX A

This appendix includes the original instruments as well as the raw data' from responses. The questionnaires are somewhat revised in order to conform to margin requirements. 
(Composite)

Name

Race

$\underline{\text { Religion }}$
FACE SHEET

$$
\text { Age } \begin{array}{r}
13-1 \\
14-1 \\
15-5 \\
16-6 \\
17-1 \\
18-1
\end{array}
$$

Sex Male - 5

Female - 10

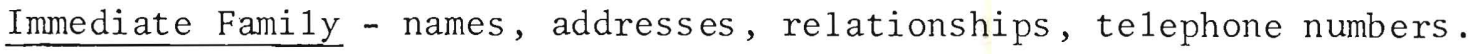

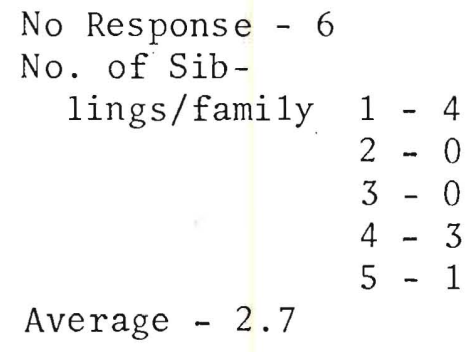

Marital status of natural parents

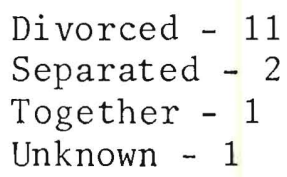

Schoo1

1. Name of the school last attended

2. Grade level

3. School achievement, good -2 average -7 poor -4

4. Any other problems

Agency History

1. Who recommended removal from the home?

2. Reason for referra1 to CSD?

3. Other alternatives attempted for care. Check any or all.
a. extended family - 7
b. counseling while remaining in the home -3
c. foster care - 11
d. residential treatment -3 


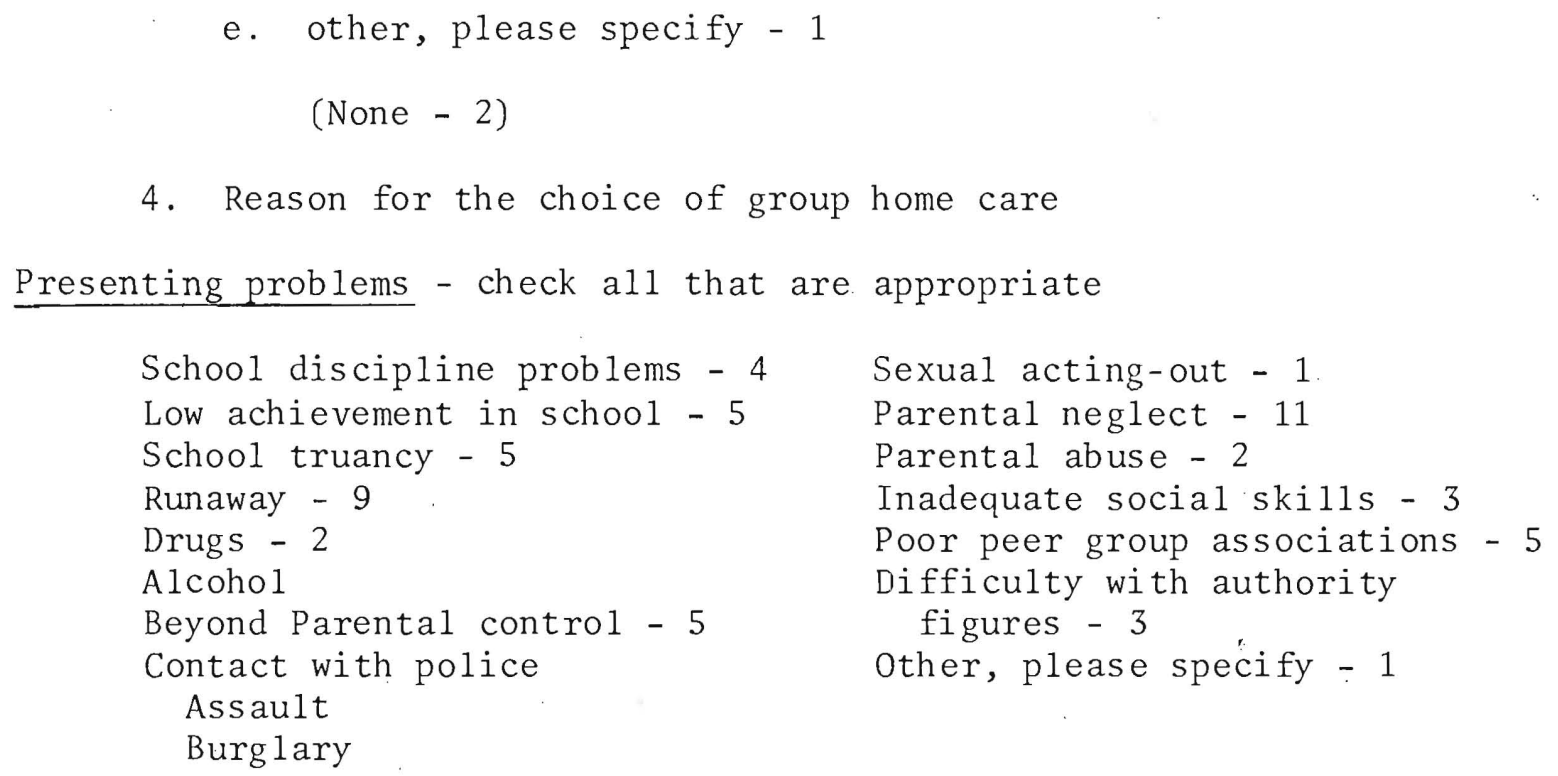

What is the level of parent involvement in threatment?

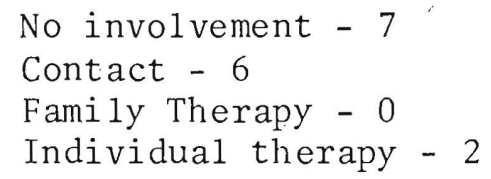

What is the nature of peer group associations?

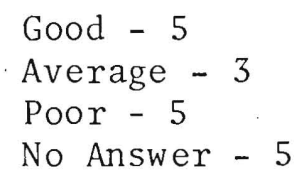

Date of Placement

Average time in group home - 5.46 months

Date of Removal 
PROVIDER QUESTIONNAIRE

1. What was the group home member's school attendance like? Please don't count excused absences.

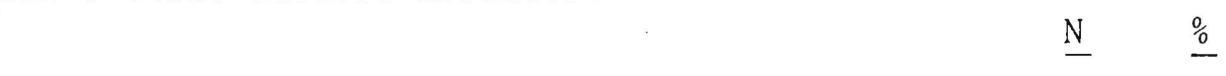

a. missed 0 days per quarter. . . . . . . . 320

b. missed 1-3 days per quarter....... . 533

c. missed 4-6 days per quarter... . . . . 531

d. missed 7-9 days per quarter . . . . . . . . 18

e. missed 10-20 days per quarter. . . . . . 00

f. missed more than 21 days per quarter . . . 188

2. Have you received any feedback from the school concerning any positive behavior on the part of the group home member during the past quarter?

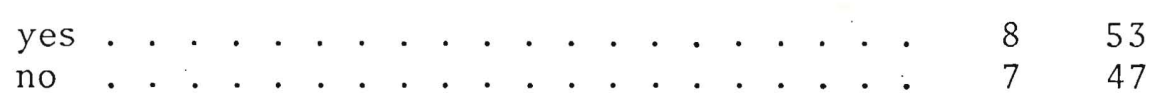

If yes: a. through what means?

b. what was the positive behavior?

c. on how many occasions?

3. Have you received any feedback on any negative behavior from. the school during the past quarter?

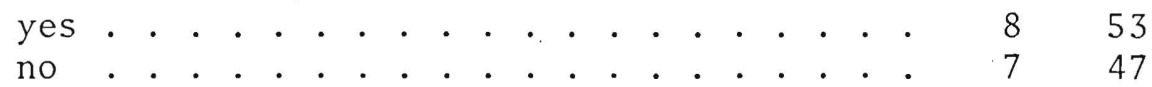

If yes: a. through what means?

b. what was the negative behavior?

c. on how many occasions?

4. Do you feel the group home, member is (Answer only if member was in the group home last quarter)

a. a good deal more interested in school this past quarter ............. . 533

b. somewhat more interested in school this. past quarter .. . . . . . . . . . 533

c. about the same?............... 2213

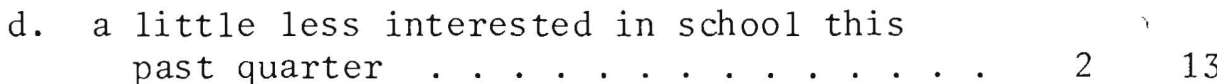

e. No Answer

5. How many classes does the group home member take?

Average $=5.54$ 
6. What were the group home member's grades? If grades are not given write down key words in the evaluation.
C1ass
Grade

1.

2.

3.

4.

5.

6.

7.

8.

9 .

10 .

7. What is the nature of the group home member's peer relationships? Please check all that are appropriate.
a. peers regard him or her as a leader... . 525

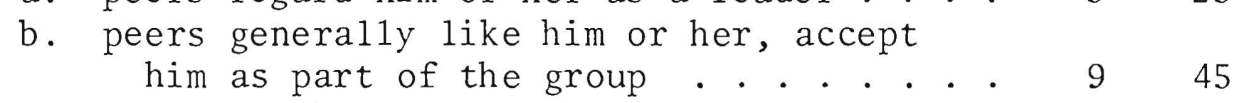
c. he or she has few friends . . . . . . . . . 525
d. peers generally dislike him or her . . . 145

8. How does the group home member deal with group decisions?
a. generally follows group decisions..... ' 640
b. follows group decisions but is sometimes
resistant............. . 640
c. is very resistant to following group
decisions............ . . 320

9. How does the group home member regard you, the provider? Check any or all.
a. as an adult friend - 12
b. as a minister - 0
c. teacher -5
d. just like them - 1
e. a relative -1
f. an older sibling - 0
g. a boss - 1
h. an aunt or uncle - 0
i. as a respected authority figure, a parent substitute - 13
j. someone who has power over him -7

10. How does the group home member react to your opinions and suggestions?
a. passive acceptance -3
b. listens and discusses issues maturely -7
c. is generally accepting and willing to interact - 6
d. is forceful about his opinions and finds it difficult to 1 isten - 5


11. How often does the group home member follow your suggestions?

\begin{tabular}{|c|c|c|c|c|}
\hline $\begin{array}{c}1 \\
\text { never }\end{array}$ & $\begin{array}{c}2 \\
\text { seldom }\end{array}$ & $\begin{array}{c}3 \\
\text { sometimes }\end{array}$ & $\begin{array}{c}4 \\
\text { often }\end{array}$ & $\begin{array}{c}5 \\
\text { always }\end{array}$ \\
\hline 0 & 0 & 5 & 8 & 2 \\
\hline 0 & 0 & 33 & 53 & 33 \\
\hline
\end{tabular}

12. How well does the group home member perform chores and duties around the home?

$\begin{array}{cccccc} & 1 & 2 & 3 & 4 & 5 \\ & \text { never } & \text { seldom } & \text { sometimes } & \text { often } & \text { always } \\ \mathrm{N} & 2 & 3 & 2 & 3 & 5 \\ \frac{\mathrm{\sigma}}{6} & 13 & 20 & 13 & 20 & 33\end{array}$

13. How often does the group home member follow house rules, i.e., quiet hours, curfew, etc.?

$\begin{array}{ccccc}1 & 2 & 3 & 4 & 5 \\ \text { never } & \text { seldom } & \text { sometimes } & \text { often } & \text { always } \\ 2 & 3 & 1 & 7 & 2 \\ 13 & 20 & 7 & 46 & 13\end{array}$

14. Has he or she run from the home?

$$
\text { yes - } 5 \text { no }-10
$$

15. If so, how many times?

16. What were his reasons for running?

17. Has he or she had any contacts with the law since being in the home? This includes being talked to by policemen, detained in JDH and major law violations.

yes - 4 no -11

18. What was the nature of the contact with the law, if any?

N $\quad \frac{\%}{0}$
a. runaway . . . . . . . . . . . . . . . . . . 1
b. theft................ . 0
c. curfew ................ . 1
d. assault . . . . . . . . . . . . . 1
e. disturbing the peace .......... 0
f. drugs . . . . . . . . . . . . . . . . 0
g. other, please explain. . . . . . . . . . 1 
19. Please check off any of the following topics that you have discussed with the group home member.

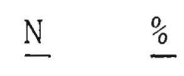

a. sex education and information . . . . . 13

b. contraception . . . . . . . . . . . 10

c. drug information . . . . . . . . . . . . . 13

d. alcohol . . . . . . . . . . . . . . 14

e. boy-girl relationships . . . . . . . . 12

f. family situation . . . . . . . . . . . . 15

g. school . . . . . . . . . . . . . . . . 15

h. friendships. . . . . . . . . . . . . . . . 13

i. their goals in life... . . . . . . . . . 13

20. Do they trust you with personal information and confidences?
a. yes................... . . 747
b. occasionally . . . . . . . . . . . . . . 533
c. very rarely............... 320
d. never............... . . 000

21. How do you see improvement or change for this group home member since he or she has been a resident?

a. peer group relationships

\begin{tabular}{|c|c|c|c|c|}
\hline 1 & 2 & 3 & 4 & 5 \\
\hline worse & & no change & & much improvement \\
\hline $\mathrm{N} \quad 0$ & 0 & 2 & 10 & 3 \\
\hline 0 & 0 & 13 & 66 & 20 \\
\hline
\end{tabular}

b. relationships with houseparents or authority figures

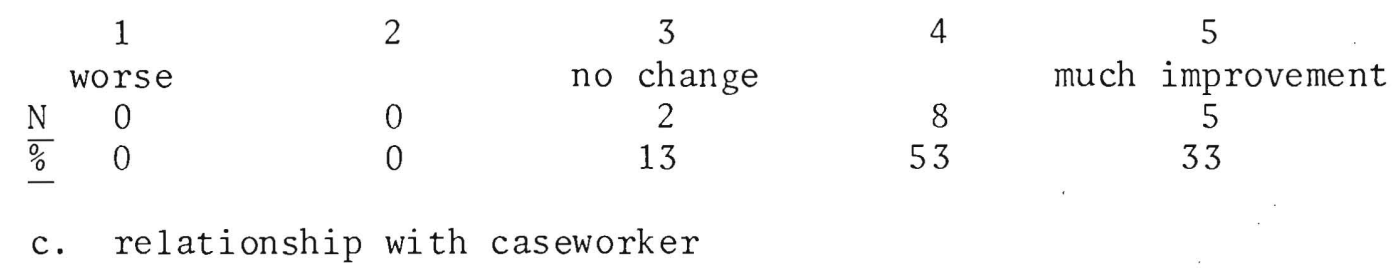

\begin{tabular}{|c|c|c|c|c|}
\hline 1 & 2 & 3 & 4 & 5 \\
\hline worse & & no change & & much improvement \\
\hline 0 & 0 & 4 & 8 & 3 \\
\hline 0 & 0 & 27 & 53 & 20 \\
\hline
\end{tabular}

d. relationship with family, if applicable

\begin{tabular}{|c|c|c|c|c|}
\hline 1 & 2 & 3 & 4 & 5 \\
\hline worse & & no change & & much improvement \\
\hline 1 & 0 & 7 & 5 & 2 \\
\hline 7 & 0 & 47 & 33 & 13 \\
\hline
\end{tabular}


22. How much insight do you feel this group home member has about the nature of his problems?

$\begin{array}{ccccc}\begin{array}{l}1 \\ \text { no insight }\end{array} & 2 & 3 & 4 & \begin{array}{c}5 \\ \text { very high de- } \\ \text { gree of insight }\end{array} \\ \frac{N}{0} & & & & 2 \\ 0 & 1 & 6 & 6 & 13\end{array}$

23. To what extent is the group home member working on his problems?

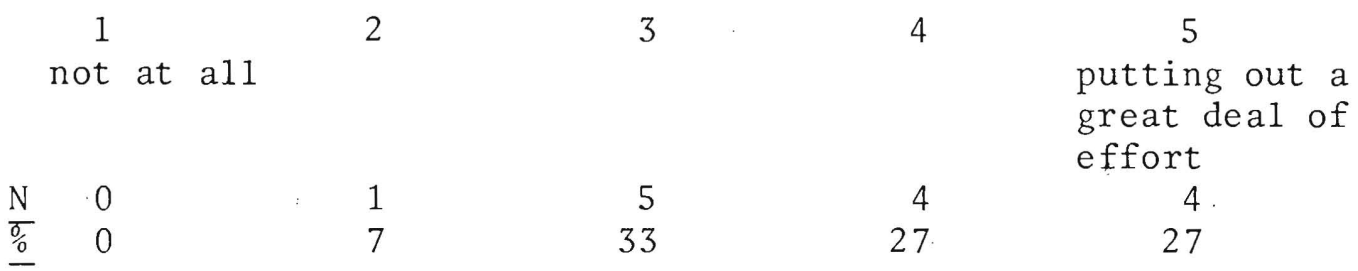

24. To what extent is the group home member aware of his strengths?

\begin{tabular}{|c|c|c|c|c|c|}
\hline 1 & 2 & 3 & 4 & & 5 \\
\hline not at all & & & & very & aw are \\
\hline $\begin{array}{ll}N & 1\end{array}$ & 3 & 6 & 3 & & 2 \\
\hline 7 & 20 & 40 & 20 & & 20 \\
\hline
\end{tabular}

25. Are there any specific treatment goals or contracts between you and the group home member?

$$
\text { yes }-13,87 \% \text { no }-1,7 \% \text { N/A }-1
$$

If so, have you seen progress in these stated goal areas?

\begin{tabular}{|c|c|c|c|c|}
\hline 1 & 2 & 3 & 4 & 5 \\
\hline worse & & same & & much progress \\
\hline $\mathrm{N} \quad 0$ & 0 & 5 & 7 & 2 \\
\hline 0 & 0 & 33 & 47 & 13 \\
\hline
\end{tabular}

26. Any additional comments. 
We are currently involved in an evaluation to determine the effectiveness of the CSD group home program. One of the determinants of the value of the group home experience is the child's performance at school.

We would appreciate it if you would take the time to answer this questionnaire to the best of your ability. Thank you.

I. Attendance

A. In the past quarter the student had (in your class) -

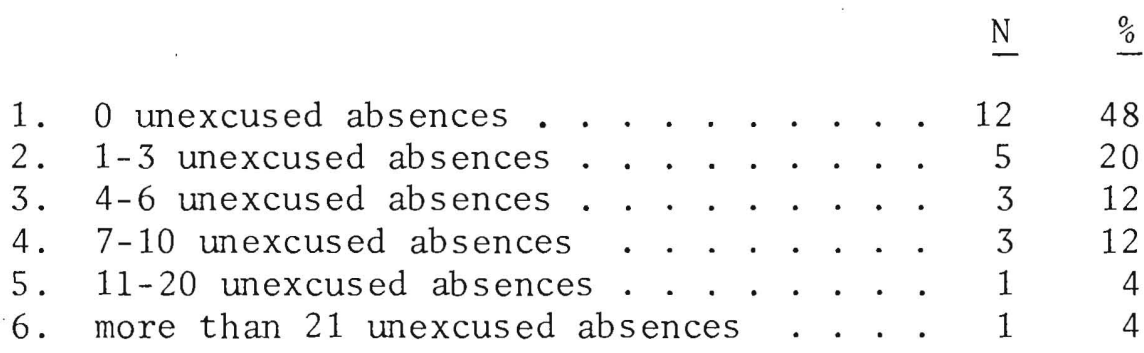

B. If possible, what was the exact number of unexcused absences? Average - 1.47

C. Any comments?

D. Was the student tardy for class -

1. almost every class that he/she attended $\begin{array}{ll}1 & 4\end{array}$

2. many of the classes that he/she attended $4 \quad 16$

3. some of the classes that he/she attended $11 \quad 44$

4. none of the classes that he/she attended 936

II. School Attitude

A. What sentence best describes the student's attitude in your clas sroom?

1. The student provided active input through class participation and was an attentive member of the class. . . . . . . 936

2. The student provided little, if any, input

through class participation, but was attentive . . . . . . . . . . . . . 12 
3. The student provided no input through

class participation and was inatten-

tive in class......... . 312

$$
\mathrm{N} / \mathrm{A}-1
$$

B. Which clause best completes the following sentence: The student's general behavior in class was -

1. one of positive leadership, directing

the class towards positive behavior. . 624

2. one of negative leadership, directing the

class towards negative behavior. . . 24

3. one of negative and positive leadership, directing the class, at different

times, towards both negative and

positive classroom behavior. . . . 312

4. neither positive nor negative leadership

concerning classroom behavior, but

can be influenced by negative

leadership . . . . . . . . . . . . 1040

5. other:

$$
\begin{array}{cc}
- & 3 \\
\text { N } / A-1 & -1
\end{array}
$$

C. The student's classroom behavior -

1. improved a great deal over the past quarter............. . 4416

2. improved somewhat over the past quarter............ . . 624

3. remained the same over the past quarter ............ 1040

4. regressed somewhat over the past quarter............. 28 .

5. regressed a great deal over the past quarter............. 000

$$
\mathrm{N} / \mathrm{A}-3
$$


D. From your impressions, the student's interest in

the class -

1. improved a great dea1 over the past

quarter............. 416

2. improved somewhat over the past

quarter........... . 520

3. remained the same over the past

quarter............ . 936

4. regressed somewhat over the past

quarter............ 312

5. regressed a great deal over the past quarter.............. . . 000

$\mathrm{N} / \mathrm{A}-4$

E. From your knowledge of the student, what sentence best describes the student's interest in extra-curricular activities at the school?

1. The student is actively involved in more than one extra-curricular activity. . $\quad 3 \quad 12$

2. The student is involved in one extracurricular activity. . . . . . . 0.0

3. The student is not involved in any extra-curricular activity . . . . . 624

4. I do not know of the involvement of the student in extra-curricular activity. . . . . . . . . . . . . . 1298 N/A -4

F. Any comments on this section of "Student Attitude?"

III. Achievement

A. How would you describe the student's academic progress since the previous quarter? (Place an " $x$ " in appropriate area.)

$\begin{array}{rrrrrr}\mathrm{N} & 2 & 8 & 7 & 2 & 2 \\ \frac{\mathrm{O}}{0} & 8 & 32 & 28 & 8 & 8\end{array}$

No academic Some acad. Making satis- More than Excellent progress progress, factory acad. satisfac- progress but not progress. tory protoo much. gress. 
B. The grade assigned to the student the past quarter was -

$B_{1}$. If grades are not given, could you write down a few key words describing the student's academic work in the past quarter?

C. Any comments concerning the student's achievement?

Thank you very much for taking the time to answer our questionnaire. 
GROUP HOUSE MEMBER QUESTIONNAIRE.

I. School

A. Attendance

1. What was your school attendance like last quarter? Do not include those days you were sick or had an excuse to miss school. In other words, how many days did you cut the entire day, if any? (If you cannot recall the specific number just check off the box that seems to come closest.)

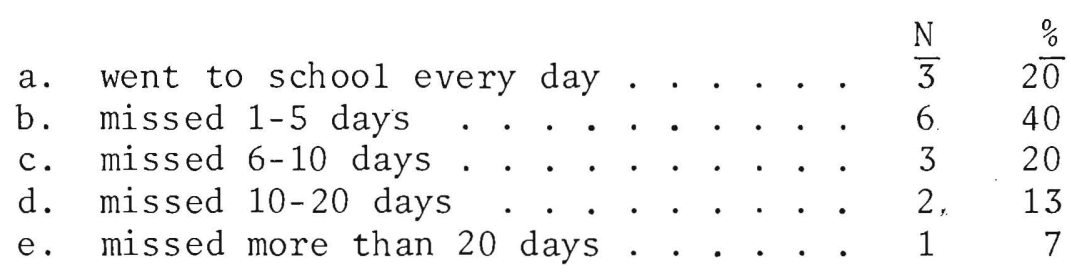

2. Last quarter when you were in school did you usually -

a. go to all of your classes . . . . 862

b. miss one class per week (If you were excused from class do not count

it) . . . . . . . . . . . . . 323

c. miss a few $(2-5)$ classes per week . 00

d. miss at least one class per day . . 118

e. miss 2 classes per day....... 000

f. miss 3 or more classes per day . . 1 . . 8

3. Do you go to classes

a. more this past quarter than last . . 4 427

b. less this past quarter than last . . 1 7

c. about the same both quarters . . . 1066

4. Answer No. 4 only if the answer to No. 3 is "more". If not, go to the next question.

I go to classes more because: (" $X$ " the sentence that seems to be the most true, if more than one sentence seems true " $X$ " all of them and write down next to the " $X$ " which sentence is most important (2), etc.)
a. classes are more interesting. . . 222
b. friends have encouraged me to go to more classes........... $0 ; 0$
c. I've become worried that I might not graduate.............. 112
d. the group home providers have influ- enced my decision to attend classes more . . . . . . . . . . . . . 333
e. other reason

$3 \quad 33$


5. Since last quarter, how would you rate your attitude about school? (put an " $\mathrm{X}$ " whenever it seems to best describe how you fee1)

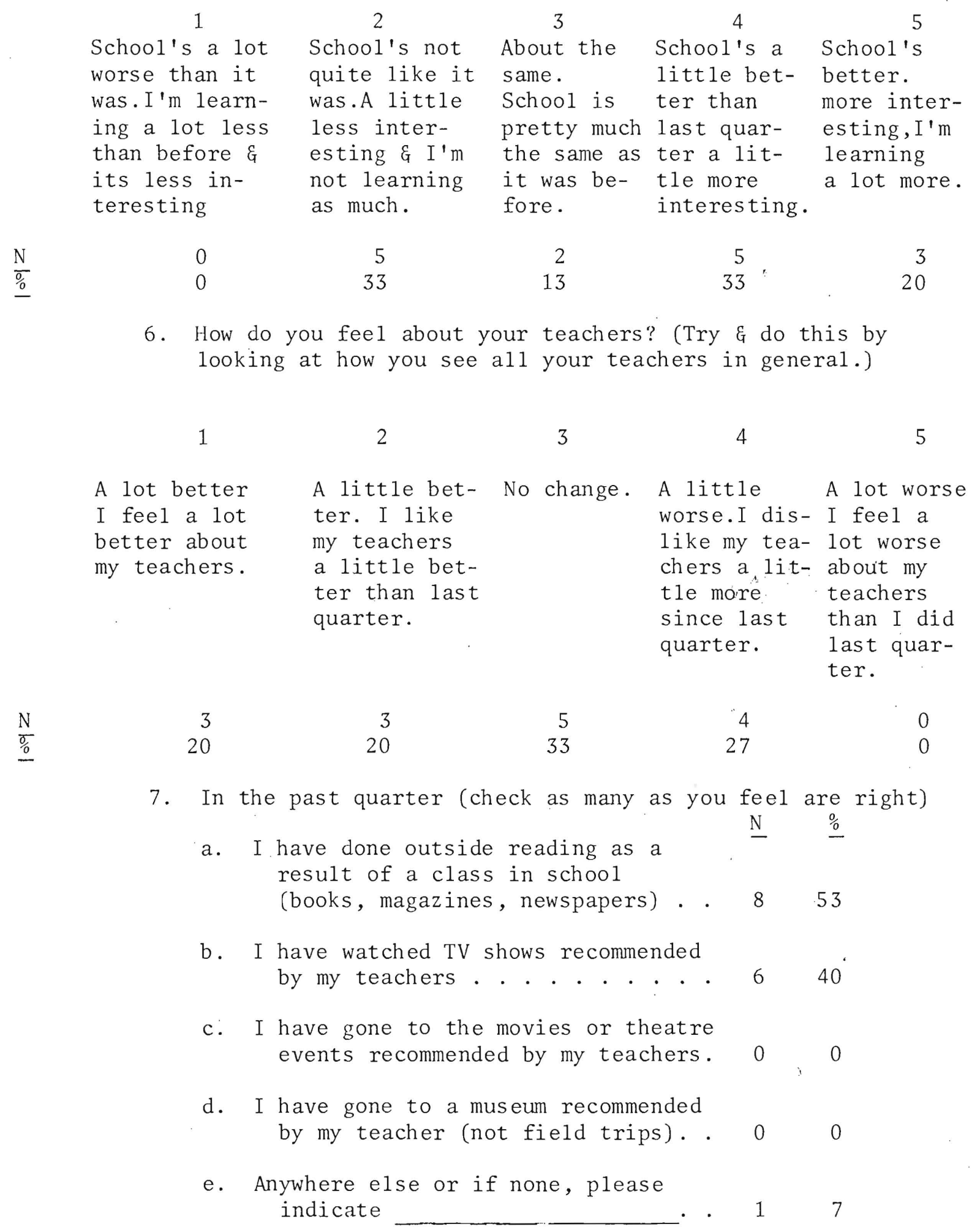


II . Home

A. Peer Relationships (the word peer means people near your age that you hang out with).

1. Describe your acceptance by your peer group.

I feel my peers:

\begin{tabular}{|c|c|c|c|c|}
\hline $\begin{array}{l}\quad 1 \\
\text { never accept } \\
\text { me. }\end{array}$ & $\begin{array}{l}\quad 2 \\
\text { seldom ac- } \\
\text { cept me. }\end{array}$ & $\begin{array}{c}3 \\
\text { sometimes } \\
\text { accept me. }\end{array}$ & $\begin{array}{c}4 \\
\text { usually } \\
\text { accept me. }\end{array}$ & $\begin{array}{l}\quad 5 \\
\text { always } \\
\text { accept } \\
\text { me. }\end{array}$ \\
\hline 0 & 1 & 1 & 8 & 5 \\
\hline 0 & 7 & 7 & 53 & 33 \\
\hline
\end{tabular}

2. Describe your level of regard or respect that you generally have for your peers.

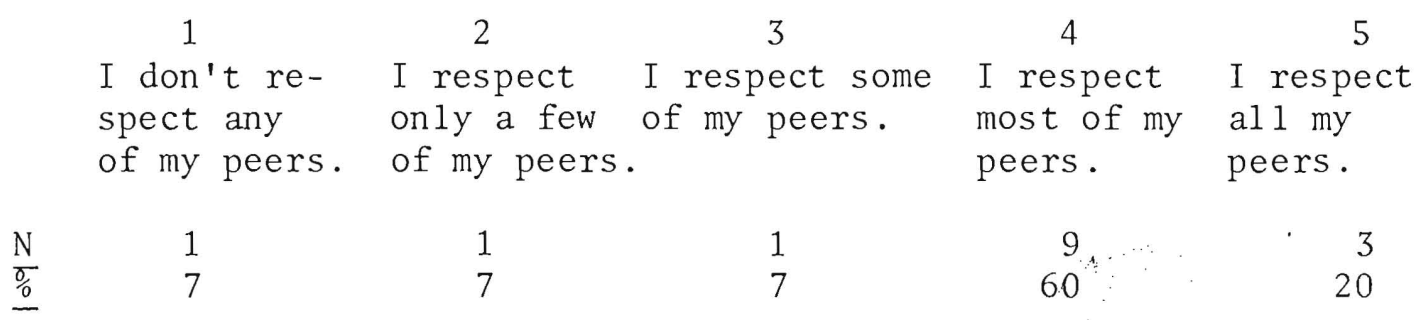

3. When I make an agreement as a group home member with other members of the home I:
a. Always keep the contract or
N $\quad \stackrel{\circ}{-}$ agreement . . . . . . . . . . . 427
b. Usually keep the contract . . . . . 747
c. Occasionally keep the contract . . 2213
d. Keep it only if others have kept their part . . . . . . . . . . . . . 117
e. Hardly ever kept a contract . . . 117

4. My best friends are: (check all those that are appropriate)
a. Schoolmates of mine. . . . . . . $13 \quad 37$
b. Live in my neighborhood . . . . 720
c. Belong to organizations I am involved in.......... 000
d. Live in the group home . . . . . 7 ' 20
e. Live in the neighborhood I used to live in........... . 6417
f. Other 
B. Relationships with Group Home Parents

1. How do you see your house parents?

I see my house parents as: $\frac{N}{1}$ - just like me

(check all that are $\quad 0$ - like a minister

appropriate). 1 - like an aunt

13 - as a friend

2 - as a teacher

3 - like relatives

3 - like brothers and sisters

4 - like a boss

9 - like parents

2. How do you feel you get along with your group home parent (s).

a. I like both of them (or him/her $\quad \underline{N} \stackrel{\%}{-}$ if single parent)....... . . 1173

b. I like one of them and tolerate the other (tolerate him/her) $\quad$. $\quad 1 \quad 7$

c. I like one but dislike the other (don't get along well with him/ her.............. . 2413

d. I dislike both of them . . . . . . 17

3. How comfortable do you feel about talking over personal feelings and problems with the group home parents.

1

Hate talking I talk only with them. when I have to.
3 They are OK I talk over I talk to talk with some feel- over all but not ings \& proabout personal pro-

blems. problems \& fee1ings with them.
\begin{tabular}{lr}
$\frac{\mathrm{N}}{\mathrm{o}}$ & 2 \\
\hline & 13
\end{tabular}
2
13
3
7
3
20
47
20

4. How often do you do what the group home parents ask you.

\begin{tabular}{cccccc} 
& 1 & 2 & 3 & 4 & 5 \\
& Never & Seldom & Sometimes & Usually & Always \\
& & & & & \\
$\frac{\mathrm{N}}{0}$ & 1 & 0 & 1 & 9 & 4 \\
\hline & 7 & 0 & 7 & 45 & 27
\end{tabular}


5. Do you feel the requests made by the group home parent are:

1

Always unreas on ab $1 \mathrm{e}$
2

Frequently unreasonable
Sometimes

unreasonable

\section{4}

Frequent 1y reasonable
5

Always reason$\mathrm{ab} 1 \mathrm{e}$.

\begin{tabular}{rrrrrr}
$N$ & 0 & 1 & 5 & 5 & 4 \\
$\frac{\sigma}{0}$ & 0 & 7 & 33 & 33 & 27 \\
\hline
\end{tabular}

6. How often do you follow the ideas and suggestions of the hous eparents?

$\begin{array}{ccccc}1 & 2 & 3 & 4 & 5 \\ \text { Never } & \text { Seldom } & \text { Sometimes } & \text { Usually } & \text { A1ways } \\ 0 & 1 & 3 & 11 & 0 \\ 0 & 7 & 20 & 73 & 0\end{array}$

7. How do you feel about the opinions and suggestions of your group home parents?
a. I accept them and never question
$\underline{N} \stackrel{\%}{-}$ them .............. 0 . 0
b. I accept them but like to dis- cuss them ............ 640
c. I sometimes accept them and some- times disagree with them... . 747
d. I seldom accept them and usually disagree . . . . . . . . . . . . . 2413
e. I never accept them, mine are more important . . . . . . . . . . . . 00

8. How well do you keep commitments or promises with your group home parents?

\begin{tabular}{|c|c|c|c|c|}
\hline 1 & 2 & 3 & 4 & 5 \\
\hline Never & Seldom & Sometimes & Usually & Always \\
\hline 1 & 2 & 2 & 10 & 0 \\
\hline 7 & 13 & 13 & 67 & 0 \\
\hline
\end{tabular}

9. I feel my house parent(s) run the home because:

(check all appropriate choices)

a. They like teenagers . . . . . . . . 924

b. They get money for it . . . . . . . 513

c. They are concerned about me . . . . 821

d. They feel they are helping people . $12 \quad 32$

e. They like being parents . . . . . . 410 
10. Please check off the following topics that you have discussed with the group home house parents.

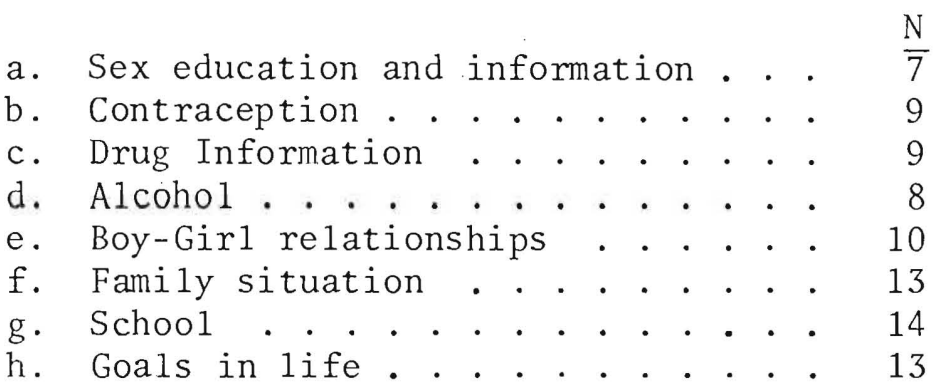

III. Cas eworker

1. To what degree do you keep agreements or promises with your caseworker?

\begin{tabular}{|c|c|c|c|c|}
\hline 1 & 2 & 3 & 4 & 5 \\
\hline Never & Seldom & Sometimes & Usua11y & A1ways \\
\hline 0 & 1 & 5 & 7 & 1 \\
\hline 0 & 7 & 33 & 47 & 7 \\
\hline
\end{tabular}

2. Is your caseworker someone:

a. Trust some of your personal thoughts

to............. . 7

b. Talk with only on a superficial or surface level......... 5

c. Put up with only because the person is your cas eworker . . . . . 3

d. Really enjoy him/her . . . . . 4

3. Do you see your caseworker as: (check as many as apply).
a. Someone with power over me . . . . 4
b. Someone you respect because the person is an expert...... . 1
c. A friend . . . . . . . . 10
d. A parent ............ . 0
e. The enemy. . . . . . . . . . . . . 0
f. Someone who gets in your way . . 0 
APPENDIX B

This Appendix contains the revised instruments. The questionnaires are somewhat revised in order to conform to margin requirements. 
FACE SHEET

Name :

Sex :

Race :

Age :

Immediate Family:

Locale:

Telephone

Numbers:

Parents

Step Parents

Siblings (ages)

Marital Status of Parents:
Married
Separated
Divorced

School

1. Name of the School 1ast attended:

2. Grade Level:

3. School Achievement: Excellent Good Fair Below Poor

4. Any other problems:

Agency History

1. Why was person referred to CSD?

2. Other alternatives attempted for care. Check any or all.
a. Extended family
b. Counseling while remaining in the home
c. foster care
d. residential treatment
e. other, please specify

3. Why was the Group Home setting chosen over other placements? 
Presenting Problems - Check all that are applicable.

School discipline problems

Low Achievement in school

School truancy

Runaway

Drugs

Alcohol

Contact with Law

Please Specify:
Parental neglect

Parental abuse

Inadequate social skills

Poor peer group associations

Difficulty with authority figures

Manipulative behavior

Physical problems

Other, please specify:

Strengths

Level of parental involvement in the treatment program

No involvement

minimal contact with child

regular contact with child Additional comments:

Nature of Peer Group Associations:

Goals for care after leaving the Group Home:

Original family

Self-sufficiency

foster care

other, please specify:

Date of Placement

Date of Removal

Last Physical exam

Last Dental exam 
PROVIDER QUESTIONNAIRE

1. What was the Group Home Member's school attendance like? Please don't count excused absences.

a. missed 0 days per quarter

b. missed 1-2 days per quarter

c. missed 3-5 days per quarter

d. missed 6-10 days per quarter

e. missed 11-20 days per quarter

f. missed 21 or more days

2. Have you received any feedback from the school (with the exception of regular evaluation reports)

yes

no

If yes, was feedback:

Positive

Negative

Please describe briefly the feedback

3. Do you fee1 the Group Home Member:

(Answer only if member was in the group home last quarter)

a. Likes school a lot more

b. Likes school a little more

c. Likes school about the same

d. Likes school a little less

e. Likes school a lot less

4. What were the Group Home Member's grades. Please be as specific as possible.

Grades

Key words

5. Describe how the Group Home Member is accepted by peers. (Circle the most appropriate number).
1
2
3
4
5

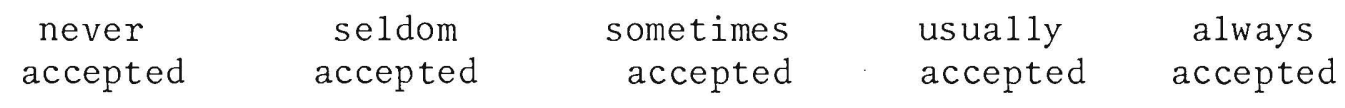


6. How does the Group Home Member accept his or her peers (Circle the most appropriate number)

1 2 3

4 5

does not Respects only Respects Respects Respects respect any a few peers. some peers. most peers. all peers. peers.

7. How does the Group Home Member deal with group decisions?

a. Generally follows group decisions

b. Follows group decisions

c. Is very resistant to following group decisions

8. How does the Group Home Member regard you, the Provider? Check any or a11.
a.. Like a friend
f. Like a cas eworker
b. Like a teacher
g. Like a brother or sister
c. Like police
d. A boss
e. Like a parent
h. Just like them
i. Like aunts or uncles

9. How does the group home member react to your opinions and suggestions?

a. Accepts them and never questions them

b. Accepts them, but likes to discuss them

c. Sometimes accepts them, and sometimes disagrees with them

d. Seldom accepts them and usually disagrees

e. Never accepts them, mine are more important

10. How often does the Group Home Member follow your suggestions?

never seldom sometimes often always

11. Does the Group Home Member perform chores and duties around the home?

a. Regularly without anyone reminding him or her

b. Regularly, but occasionally needs reminding

c. Regularly, but always has to be reminded

d. Sometimes does chores and always needs to be reminded

e. Never does chores

12. How often does the Group Home Member follow house rules, i.e., quiet hours, etc.

1

never
2

seldom
3

sometimes
4 5

often 
13. Has he or she run from the home?

14. If so, how many times?

15. What were his reasons for running?

16. Has he or she had any contacts with the law since being in the home? This includes being ticketed, given warnings by police, detained in JDH and major law violations.

17. What was the nature of the contact with the law, if any?
a. Runaway
b. Theft
c. Curfew
d. Assault
e. Disturbing the peace
f. Drugs
g. Other, please explain.

18. Please check off any of the following topics that you have discussed with the Group Home Member.
a. Sex education and information
b. Contraception
c. Drug information
d. Alcohol
e. Boy-Girl relationships
f. Family situation
g. School
h. Friendships
i. Their goals in life

19. Do they trust you with personal information and confidences?
a. yes
b. occasionally
c. very rarely
d. never

20. How do you see improvement or change for this Group Home Member since he or she has been a resident?

a. Peer group relationships

1

worse
2 3 no change
4 5 much improvement 
b. Relationships with house parents

$\begin{array}{lllll}1 & 3 & 4 & 5\end{array}$

worse no change much improvement

c. Relationship with caseworker

$\begin{array}{lllll}1 & 2 & 3 & 4\end{array}$

worse no change much improvement

21. Are there any specific treatment goals or contracts between you and the Group Home Member?
yes
no

If so, have you seen progress in these stated goals areas?

1

2

3

4

5

worse

same

much progress 
We are currently involved in an evaluation to determine the effectiveness of the CSD Group Home Program. One of the determinants of the value of the Group Home experience is the child's performance at school.

We would appreciate it if you would take the time to answer this questionnaire to the best of your ability. Thank you.

\section{Attendance}

A. In the past quarter the student had (in your class) -

1. 0 unexcused absences.

2. 1-3 unexcused absences

3. 4-6 unexcused absences

4. 7-10 unexcused absences

5. 11-20 unexcused absences

6. More than 21 unexcused absences.

B. Any comments?

C. Was the student tardy for class -

1. Almost every class that he/she attended

2. Many of the classes that he/she attended

3. Some of the classes that he/she attended

4. None of the classes that he/she attended

\section{School Attitude}

A. What sentence best describes the student's attitude in your classroom?

1. The student provided active input through class participation and was an attentive member of the class.

2. The student provided little, if any, input through class participation, but was attentive.

3. The student provided no input through class participation and was inattentive in class. 
B. Do you see the student as a -

1. Positive leader

2. Negative leader

3. Positive follower

4. Negative follower

5. Neither a leader nor a follower

C. Do you see the student as generally being -

1. A cooperative student

2. A disruptive student

3. An even mixture of both cooperative and disruptive

Comments?

D. From your impressions, the student's interest in the class -

1. improved a great deal over the past quarter

2. improved somewhat over the past quarter

3. remained the same over the past quarter

4. regressed somewhat over the past quarter

5. regressed a great deal over the past quarter

E. From your knowledge of the student, what sentence best desscribes the student's interest in extra-curricular activities at the school?

1. The student is actively involved in more than one extracurricular activity.

2. The student is involved in one extra-curricular activity.

3. The student is not involved in any extra-curricular activity.

4. I do not know of the involvement of the student in extracurricular activity.

F. Any comments on this section of "Student Attitude?"

III. Achievement

A. How would you describe the student's academic progress since the previous quarter? (Circle appropriate number)$$
1
$$

No academic progress.

$$
23
$$

Some acad. progress,but factory acad. not too much .

\section{4} More than satisfactory progress.

\section{5}

Excellent progress. 
B. In your class do you feel the student's present performance is (circle the appropriate number) -

1

Excellent

2

Good

Fair
4

Below Average

C. Other comments concerning student's academic achievement?

Thank you very much for taking the time to answer our questionnaire. 
GROUP HOUSE MEMBER QUESTIONNAIRE

I. School

A. Attendance

1. What was your school attendance like last quarter? Do not include those days you were sick or had an excuse to miss school. In other words, how many days did you cut the entire day, if any? (If you cannot recall the specific number just check off the box that seems to come closest.)
a. went to school everyday
b. missed 1-2 days
c. missed 3-5 days
d. missed 6-10 days
e. missed 11-20 days
f. missed 21 or more days

2. Last quarter (the quarter just over) when you were in school did you usually -

a. go to all of your classes

b. skipped 1-5 classes in the quarter (if you were excused from class don't count it.)

c. skipped 6-10 classes per quarter (about one class per week)

d. skipped a few (2-5) classes per week

e. skipped about 1 class per day

f. skipped about $2 \mathrm{classes}$ per day

g. skipped 3 or more classes per day

STOP Answer questions 3,4 and 5 only if you have lived in the Group Home for at least two full school quarters. If you haven't lived there that long, go to question 6 .

3. Did you go to classes -
a. more this past quarter than last.
b. less this past quarter than last
c. about the same both quarters

STOP Answer question 4 only if your answer to No. 3 was "more". If not, go to question No. 5 .

4. I go to classes more because (only " $\mathrm{X}$ " one answer)
a. Classes are more interesting
b. Friends have encouraged me to go to more classes
c. Teachers/counselors have influenced me
e. The group home providers have influenced my decision to attend classes more
f. I realize to stay in the group home I must go to classes
g. other reason (please explain) 
5. Since last quarter, how would you rate your attitude about school?

\begin{tabular}{|c|c|c|c|c|}
\hline $\begin{array}{l}1 \\
\text { school's a lot } \\
\text { worse than it } \\
\text { was. I'm learn- } \\
\text { ing a lot less } \\
\text { than before \& } \\
\text { its less } \\
\text { interesting. }\end{array}$ & $\begin{array}{l}2 \\
\text { school's not } \\
\text { quite like it } \\
\text { was.A little } \\
\text { less inter- } \\
\text { esting \& I'm } \\
\text { not learning } \\
\text { as much. }\end{array}$ & $\begin{array}{l}\text { 3 } \\
\text { about the same } \\
\text { school is pret- } \\
\text { ty much the same } \\
\text { as it was before }\end{array}$ & $\begin{array}{l}4 \\
\text { school's a lit- } \\
\text { tle better than } \\
\text { last quarter a } \\
\text { little more } \\
\text { interesting. }\end{array}$ & \begin{tabular}{l}
\multicolumn{1}{c}{5} \\
school's \\
better \\
and more \\
inter- \\
esting, \\
I'm learn- \\
ing a \\
lot more.
\end{tabular} \\
\hline
\end{tabular}

6. How do you feel about your teachers? Try and do this by looking at how you see all your teachers in general. (Circle the correct number).

123

A lot better. I feel a lot better about my teachers.
A little bet- No change ter. I like my teachers a little better than last quarter.
4

A little worse I dislike my teachers a little more since last quarter.
5
A 1 ot worse. I feel a lot worse about my teachers than I did last quarter.

7. In the past quarter (check as many as you feel are right) -

a. I have done outside reading as a result of a class in school (books, magazines, newspapers.)

b. I have watched TV shows recommended by my teachers.

c. I have gone to the movies or theatre events recommended by my teachers.

d. I have gone to a museum or exhibit recommended by my teacher (not field trips)

e. Anywhere else or if none, please indicate.

III. Home

A. Peer Relationships (the word "peer" means people near your age that you hang out with)

1. Describe your acceptance by your peer group.

I feel my peers: (Circle the most appropriate number)

$\begin{array}{lllll}1 & 2 & 3 & 4 & 5 \\ \text { never } & \text { seldom } & \text { sometimes } & \text { usually } & \text { always } \\ \text { accept } & \text { accept } & \text { accept me. } & \text { accept me. } & \text { accept } \\ \text { me. } & \text { me. } & & & \text { me. }\end{array}$


2. Describe your level of regard or respect that you generally have for your peers (Circle the most appropriate number) -

$\begin{array}{lllll}1 & 3 & 4 & 5\end{array}$

I don't res- I respect on- I respect I respect I respect pect any of $1 \mathrm{y}$ a few of some of most of ail my my peers. my peers. my peers. my peers. peers.

3. All group homes require that their members perform certain household jobs (cooking, cleaning, recycling, etc.) How do you perform these tasks? ("X" the appropriate sentence.)

a. I do them regularly without anyone reminding me.

b. I do them regularly, but occasionally need reminding

c. I regularly do them, but always need to be reminded

d. I sometimes do them, and always need to be reminded

e. I never do them.

4. How well do you follow household rules (curfews, quiet hours, etc.) (Circle the appropriate number) -

1

never

$$
2
$$

seldom
3

sometimes
4

usua11y

5. My best friends are: (check all those that are appropriate)

a. Schoolmates of mine

b. Live in my neighborhood

c. Belong to organizations I am involved in

d. Live in the group home

e. Live in the neighborhood I used to live in

f. Other

B. Relationship with Group Home Parents

1. How do you see your house parents? (Check as many as you like) -

Just like me

Like an aunt or uncle

Like a friend

Like teachers

Like police

Like brothers and sisters

Like a boss

Like parents

Like cas eworkers 
STOP Only answer No. 2 if there are 2 group parents in your home.

Only answer No. 3 if there is 1 group parent in your home.

Then go on to No. 4.

2. Generally speaking, how do you feel about your group home parents (try and answer this question by thinking how you've felt about them for a while, not the way you've felt about the past few days)
a. I like both of them
b. I like one of them and tolerate (don't like, but don't really dislike) the other.
c. I like one but dislike the other.
d. I dislike both of them.

3. Generally speaking how do you feel about your group home parent. (Try and answer this question by thinking how you've felt about her/him for a while, not the way you've felt about her/him the past few days).

a. I like him/her.

b. It's evenly divided--sometimes I like her/him.

c. I usually dislike her/him.

4. How comfortable do you feel about talking over personal feelings and problems with the group home parent(s)?
1
2
3
4
5

Hate talking I talk only They are OK I talk over I talk over with them. when I have to talk with some feel- all probbut not ings \& prob-lems \& about per- lems. feelings sonal with them. problems .

5. Do you feel the requests made by the group home parent are:
1
2
3
4
5

Always

$$
\text { Frequent1y }
$$

Sometimes

Frequent $1 y$

Always

unreasonab le

un reasonable

un reas onab 1 e reas on ab le

reas onable

6. How often do you follow the ideas and suggestions of the house parents? (Circle the appropriate number)

1

Never
2

Se1dom
4

Usually
5

Sometimes Usually Always


7. How well do you keep commitments or promises with your group home parents? (Circle the appropriate number).

1

2

3

4

5

Never Seldom Sometimes Usually Always

8. I feel my house parent(s) run the home because:

(check all appropriate choices)

a. They like teenagers

b. They get money for it

c. They are concerned about me

d. They feel they are helping people

e. They like being parents

9. Please check off the following topics that you have discussed with the group home house parents. (Check all that you've talked about).

a. Sex education and information

b. Contraception

c. Drug Information

d. Alcohol

e. Boy-Girl relationships

f. Family situation

g. Schoo 1

h. Friendships

i. Goals in life

10. How do you feel about the opinions and suggestions of your group home parents: (Check only one).

a. I accept them and never question them

b. I accept them but like to discuss them

c. I sometimes accept them and sometimes disagree with them.

d. I seldom accept them and usually disagree

e. I never accept them, mine are more important.

III. Cas eworker

1. To what degree do you keep agreements or promises with your caseworker? (Circle the appropriate number)

$\begin{array}{lllll}1 & 2 & 3 & 4\end{array}$

Never Seldom Sometimes Usually Always 
2. Do you see your caseworker as (check as many as apply)

a. Someone who is like a parent

b. Someone I respect because she/he knows what he/she is talking about.

c. Someone like a good friend, who I can share my personal thoughts with

d. Someone who I dislike, because they try and control my life too much.

e. Other

IV. Community

1. Have you had any contacts with the law since being in the Group Home? (This includes being ticketed, 'given a warning, going to JDH, or a major law violation).

$$
\text { Yes No }
$$

2. If yes, what happens? (If no, go to question No. 3)

3. Do you have a job? (Include any temporary jobs, such as babysitting, lawn care, etc.)

$$
\text { Yes No }
$$

4. If yes, how many hours do you work per week? (If no, go to question No. 5)

5. Are you involved in any other community activities, such as (Check a11 that apply) -

volunteer jobs

classes outside of school

organized outdoor or sporting/athletic programs

Clubs (in-schoo1)

Clubs (outside school)

Other 